\title{
IgG4 Characteristics and Functions in Cancer Immunity
}

\author{
Silvia Crescioli ${ }^{1,2} \cdot$ Isabel Correa ${ }^{1,2} \cdot$ Panagiotis Karagiannis $^{1,2} \cdot$ Anna M. Davies $^{3,4}$ • \\ Brian J. Sutton $^{3,4}$ • Frank O. Nestle ${ }^{1,2}$ - Sophia N. Karagiannis ${ }^{1,2,5}$
}

Published online: 7 January 2016

(C) The Author(s) 2016. This article is published with open access at Springerlink.com

\begin{abstract}
IgG4 is the least abundant subclass of IgG in normal human serum, but elevated IgG4 levels are triggered in response to a chronic antigenic stimulus and inflammation. Since the immune system is exposed to tumor-associated antigens over a relatively long period of time, and tumors notoriously promote inflammation, it is unsurprising that IgG4 has been implicated in certain tumor types. Despite differing from other IgG subclasses by only a few amino acids, IgG4 possesses unique structural characteristics that may be responsible for its poor effector function potency and immunomodulatory properties. We describe the unique attributes of IgG4 that may be responsible for these regulatory functions, particularly in the cancer context. We discuss the inflammatory
\end{abstract}

This article is part of the Topical Collection on Immune Deficiency and Dysregulation

\author{
Sophia N. Karagiannis \\ sophia.karagiannis@kcl.ac.uk \\ Silvia Crescioli \\ silvia.crescioli@kcl.ac.uk \\ Isabel Correa \\ isabel.correa@kcl.ac.uk \\ Panagiotis Karagiannis \\ panos.karagiannis@kcl.ac.uk \\ Anna M. Davies \\ anna.davies@kcl.ac.uk \\ Brian J. Sutton \\ brian.sutton@kcl.ac.uk \\ Frank O. Nestle \\ frank.nestle@kcl.ac.uk
}

1 St. John's Institute of Dermatology, Division of Genetics and Molecular Medicine; Faculty of Life Sciences and Medicine, King's College London, London, UK conditions in tumors that support $\mathrm{IgG4}$, the emerging and proposed mechanisms by which IgG4 may contribute to tumor-associated escape from immune surveillance and implications for cancer immunotherapy.

Keywords IgG4 · Cancer · Immune escape · Antibodies · Effector functions $\cdot$ Immunotherapy
Abbreviations
Ig Immunoglobulin
$\mathrm{V}_{\mathrm{L}} \quad$ Light chain variable domain
$\mathrm{V}_{\mathrm{H}} \quad$ Heavy chain variable domain

2 NIHR Biomedical Research Centre at Guy's and St. Thomas's Hospitals and King's College London, King's College London, London, UK

3 Randall Division of Cell and Molecular Biophysics, Faculty of Life Sciences and Medicine, King's College London, London, UK

$4 \quad$ Medical Research Council \& Asthma UK Centre in Allergic Mechanisms of Asthma, London, UK

5 St. John's Institute of Dermatology, Division of Genetics and Molecular Medicine, Kings' College London and NIHR Biomedical Research Centre at Guy's and St. Thomas's Hospitals and King's College London, Guy's Hospital, Tower Wing, 9th Floor, London SE1 9RT, UK 


$\begin{array}{ll}\text { CDRs } & \text { Complementarity determining regions } \\ \mathrm{C}_{\mathrm{H}} & \text { Constant domain } \\ \mathrm{Fab} & \text { Fragment antigen binding } \\ \mathrm{Fc} & \text { Fragment crystallizable } \\ \mathrm{HL} & \text { Heavy chain/light chain half molecule } \\ \mathrm{CSR} & \text { Class switch recombination } \\ \mathrm{SHM} & \text { Somatic hypermutation } \\ \mathrm{AID} & \text { Activation-induced cytidine deaminase } \\ \mathrm{IL} & \text { Interleukin } \\ \text { VEGF } & \text { Vascular endothelial growth factor } \\ \text { Fc } \gamma \mathrm{R} & \text { Fc } \gamma \text { receptor } \\ \text { FAE } & \text { Fab-arm exchange } \\ \mathrm{CDC} & \text { Complement dependent cytotoxicity } \\ \text { ADCC } & \text { Antibody-dependent cellular cytotoxicity } \\ \text { ADCP } & \text { Antibody-dependent cellular phagocytosis }\end{array}$

\section{Introduction}

\section{IgG Structure}

The four human IgG subclasses were discovered in the $1960 \mathrm{~s}$ and named according to their time of discovery and order of their relative abundance in human serum (approximately IgG1, $61 \%$; IgG2, $32 \%$; IgG3, $4 \%$; and IgG4, $3 \%$ ) [1, 2•]. IgGs are heterotetrameric glycoproteins composed by two identical light chains and two identical heavy chains. Each chain comprises a series immunoglobulin domains [3]. Heavy chains $(\gamma 1, \gamma 2, \gamma 3$, or $\gamma 4, \sim 50 \mathrm{kDa})$ are composed of an $\mathrm{N}$-terminal variable domain $\left(\mathrm{V}_{\mathrm{H}}\right)$ followed by three constant domains $\left(\mathrm{C}_{\mathrm{H}} 1, \mathrm{C}_{\mathrm{H}} 2\right.$, and $\left.\mathrm{C}_{\mathrm{H}} 3\right)$. Light chains ( $\mathrm{\kappa}$ or $\lambda$, $\sim 25 \mathrm{kDa}$ ) are composed of an $\mathrm{N}$-terminal variable domain $\left(\mathrm{V}_{\mathrm{L}}\right)$ and a constant domain $\left(\mathrm{C}_{\mathrm{L}}\right)$.

Light chain $\mathrm{V}_{\mathrm{L}}$ and $\mathrm{C}_{\mathrm{L}}$ domains are paired with heavy chain $\mathrm{V}_{\mathrm{H}}$ and $\mathrm{C}_{\mathrm{H}} 1$ domains, respectively, to form the fragment antigen-binding (Fab) arms. The complementaritydetermining regions (CDRs) from the $\mathrm{V}_{\mathrm{H}}$ and $\mathrm{V}_{\mathrm{L}}$ domains form the antigen-binding site. Between the $\mathrm{C}_{\mathrm{H}} 1$ and $\mathrm{C}_{\mathrm{H}} 2$ domains lies the flexible hinge, which connects the Fab to the fragment crystallizable ( $\mathrm{Fc}$ ) region, comprising $\mathrm{C}_{\mathrm{H}} 2$ and $\mathrm{C}_{\mathrm{H}} 3$ domains. The $\mathrm{Fc}$ region is involved in antibody effector functions, engaging complement or Fc $\gamma$ Rs to trigger activation of immune effector cells. The two light/heavy chain (HL) pairs are joined to form the whole antibody through covalent and non-covalent interactions between the heavy chains (Fig. 1a).

IgG4 contains unique structural features in the hinge, $\mathrm{C}_{\mathrm{H}} 2$ and $\mathrm{C}_{\mathrm{H}} 3$ domains, that are thought to be responsible for its structural properties, binding characteristics and reduced effector function, compared to other subclasses.
Fig. 1 Structural and functional features of IgG4. a IgG4 structure: $(i)$ IgG architecture. The Fab comprises $\mathrm{V}_{\mathrm{H}}, \mathrm{V}_{\mathrm{L}}, \mathrm{C}_{\mathrm{H}} 1$, and $\mathrm{C}_{\mathrm{L}}$ domains. The Fc region comprises $\mathrm{C}_{\mathrm{H}} 2$ and $\mathrm{C}_{\mathrm{H}} 3$ domains, and the hinge connects the $\mathrm{Fab}$ to the Fc. In IgG1, two disulfide bonds (black lines) covalently link the two heavy chains. (ii) The core hinge. In IgG1, residues 226-229 from the core hinge are CPPC. Inter-heavy chain disulfide bonds form between Cys226 and Cys229 (blue lines). Residues 226-229 are CPSC. In addition to the hinge disulfide bond pattern in IgG1, intra-heavy chain disulfide bonds can form between Cys226 and Cys229 (orange lines). (iii) Structure of the $\operatorname{IgG~C}_{\mathrm{H}} 2$ domain. The IgG1 and $\mathrm{IgG} 4 \mathrm{C}_{\mathrm{H}} 2$ domains are colored in pink and blue, respectively. While the overall fold of the $\mathrm{C}_{\mathrm{H}} 2$ domains is similar, in $\mathrm{IgG} 4$, the $\mathrm{C}_{\mathrm{H}} 2$ domain $\mathrm{FG}$ loop adopts a unique conformation. (iv) Crystal structure of the IgG4-Fc region. The two heavy chains are colored in blue and orange. Arg409, positioned at the interface of the $\mathrm{C}_{\mathrm{H}} 3-\mathrm{C}_{\mathrm{H}} 3$ domain dimer, is colored in red. $\mathbf{b}$ Proposed mechanisms of IgG4 blockade in cancer. Tumor-associated humoral immunity could promote tumor suppression or progression (left and right of dotted line, respectively). Rapid production of anti-tumor IgG1 can eliminate antigen-expressing tumor cells through $\mathrm{CDC}, \mathrm{ADCC}$, and ADCP. Chronic antigen persistence along with a Th2-biased cytokine milieu (IL-4, IL-10, VEGF) expressed by resident Tregs and tumor cells can support sequential CSR of B cells to IgG4. IgG4 might thus be more affinity matured than clonally related $\mathrm{IgG1}$ and may compete with IgG1 for binding tumor antigens. IgG4 could also undergo Fab-arm exchange with other IgG4s, resulting in functionally monovalent antibodies or antibodies with increased avidity. Inability of IgG4 to fix complement and to bind activating $\mathrm{Fc} \gamma \mathrm{Rs}$ on immune effector cells may result in blockade of antibody-mediated $\mathrm{CDC}, \mathrm{ADCC}$, and ADCP. Alternatively, binding of IgG4 to the inhibitory Fc $\gamma \mathrm{RIIb}$ with higher affinity than other IgG subclasses could form ICs together with other antibodies, such as IgG1, co-engaging Fc $\gamma$ RIIb and activating Fc $\gamma$ Rs, dampening Fc $\gamma \mathrm{R}$-mediated functions. Also, in the proteolytic conditions of tumor microenvironments (e.g., MMP), IgG1 bound to tumors could be cleaved on one heavy chain, causing partial dissociation and facilitating IgG4-Fc binding. This could interfere with IgG1-mediated effector functions or trigger intracellular uptake and clearance of the target from tumor cell surfaces

\section{IgG Production by B Cells and Class Switching}

Proliferating B cells undergo class switch recombination (CSR), enabling them to produce antibodies with the same antigen specificity, but different isotypes (and subclasses), with different Fc regions, and consequently different effector functions. This affords the flexibility to develop a variety of immune responses against the same target, immediately upon antigenic stimulation or in a temporal manner. CSR entails intra-chromosomal DNA recombination between the region located downstream the Variable Diversity Joining segments (VDJ) region (that encode $\mathrm{V}_{\mathrm{H}}$ ) and the region upstream (a specific $\mathrm{C}_{\mathrm{H}}$ gene). The process is triggered by the enzyme activation-induced cytidine deaminase (AID). CSR occurs when B cells are stimulated by T cells in the germinal centers, and the switch toward one specific class is dependent on the cytokine milieu in the B cell microenvironment [4]. Isotype switching to both $\mathrm{IgG} 4$ and $\mathrm{IgE}$ is known to be promoted by Th2-type cytokines (IL-4, IL-13) and by B and T cell interaction through CD40:CD40-ligand [5, 6]. While in the so-called Th2-biased response, biased expression of the cytokines IL-10, VEGF, [6, 7], IL-12 [8], and IL-21 [8, 9] have been reported to skew class switching toward IgG4. 


\section{a) IgG4 structure}

i)

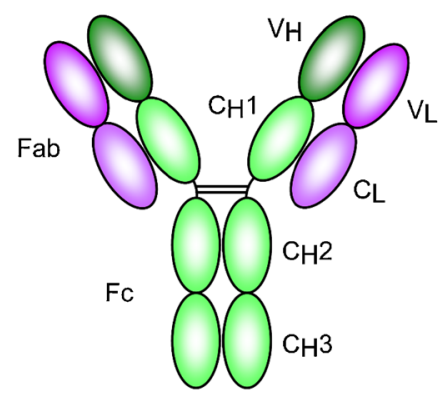

ii)

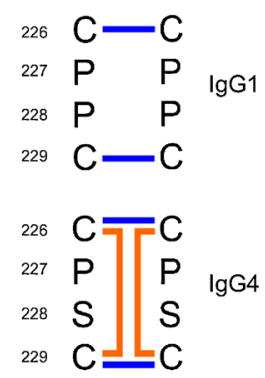

iii)

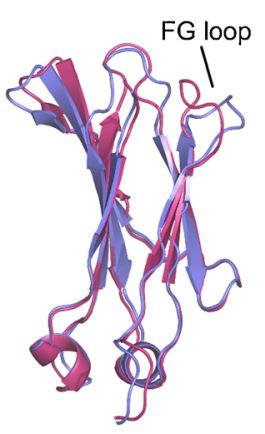

iv)

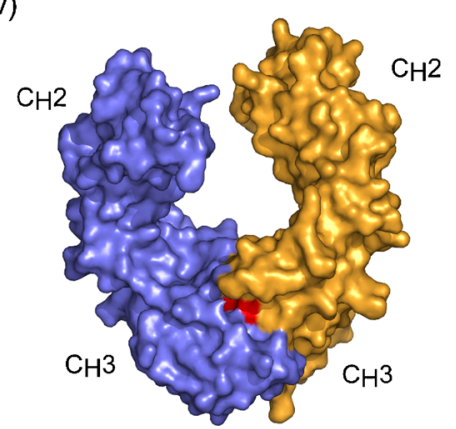

b) Mechanisms of IgG4 blockade in cancer
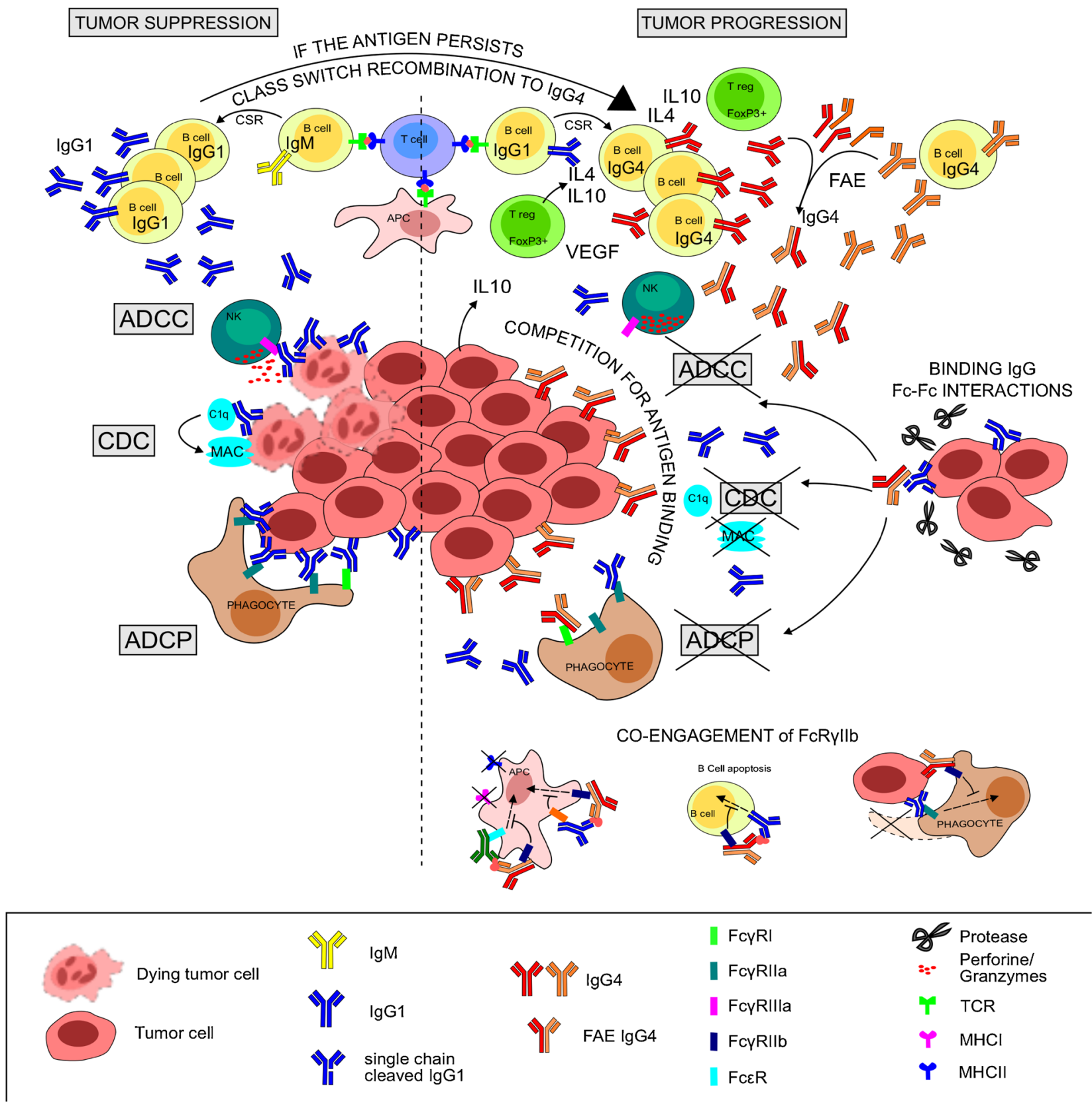


\section{Binding Characteristics of IgG Subclasses for Fc $\gamma$ Receptors}

Human Fc $\gamma$ Rs are expressed in different immune cells subsets (Table 1) [10-12] and can be divided into two groups depending on their ability to bind monomeric IgG (high-affinity receptors) or exclusively IgG immune complexes (IC) (lowaffinity receptors) [13]. There are three families of Fc $\gamma$ Rs. Fc $\gamma$ RI (CD64) is the only high-affinity receptor. The other two families comprise the low-affinity receptors, Fc $\gamma$ RII (CD32) and Fc $\gamma$ RIII (CD16). The Fc $\gamma$ RII family comprises Fc $\gamma$ RIIa, Fc $\gamma$ RIIb , and Fc $\gamma$ RIIc, while the Fc $\gamma$ RIII family comprises Fc $\gamma$ RIIIa and Fc $\gamma$ RIIIb [10]. Fc $\gamma$ Rs are functionally divided into activating and inhibitory receptors. All the receptors have activating properties except Fc $\gamma$ RIIb which is inhibitory, and FcyRIIIb whose function is uncertain. The affinity of IgG4 for Fc $\gamma$ RI is of the same order of magnitude as $\mathrm{IgG1}$ and $\mathrm{IgG} 3$, while IgG4 binds to the other activating receptors with lower affinity. The affinity of IgG4 for the inhibitory Fc $\gamma$ RIIb is similar or even higher than that of the other subclasses (Table 1) [12].

The poor affinity of IgG4 for the activating receptors, except Fc $\gamma$ RI, results in an impaired ability to engage immune effector cells compared to IgG1, its characteristics and its relevance in cancer are discussed in this review [14].

\section{Characteristics that Give IgG4 Distinct Binding and Functional Properties}

Although the constant heavy chain regions of different $\operatorname{IgG}$ subclasses share over $95 \%$ sequence homology, their structures and effector functions differ. IgG4 in particular has unique characteristics that may be responsible for its antiinflammatory properties and less potent effector function compared with IgG1 and IgG3 [15]. Throughout this review, amino acids are indicated using the single letter code and their position is indicated according to the EU-index numbering [16].

\section{The Hinge and $\mathrm{C}_{\mathrm{H}} 2$ Domains Are Responsible for Poor Binding to $\mathrm{C} 1 \mathrm{q}$ and $\mathrm{Fc} \gamma \mathrm{Rs}$}

The structure of IgG4 combines a short hinge and low Fabarm flexibility [17]. Since the composition and length of the hinge affects the conformation and the flexibility of the Fab arms relative to each other, and relative to the $\mathrm{Fc}$ region, the orientation of the IgG4 Fab arms may partly shield the $\mathrm{C} 1 \mathrm{q}$ and $\mathrm{Fc} \gamma \mathrm{R}$ binding sites on the $\mathrm{C}_{\mathrm{H}} 2$ domain $[18,19]$.

Together with the lower hinge region, the FG loop (loop between strand $F$ and strand $G$ ) from the $\mathrm{C}_{\mathrm{H}} 2$ domain is also known to be crucial for $\operatorname{IgG}$ binding to Fc $\gamma$ Rs $[20,21]$ and to C1q $[22,23]$. Recent high resolution crystal structures of human IgG4-Fc showed that the FG loop in the IgG4 $\mathrm{C}_{\mathrm{H}} 2$ domain can adopt a unique conformation that disrupts the $\mathrm{C} 1 \mathrm{q}$ and Fc $\gamma \mathrm{R}$ binding sites [24••] (Fig. 1a).

These features combined could be responsible for the poor ability of IgG4 to engage C1q and Fc $\gamma$ Rs and could result in low capacity to trigger effector functions.

\section{Fab-arm Exchange Affects Bivalency}

A distinct property of IgG4 is its ability to undergo a process termed Fab-arm exchange, in which "half molecules," each comprising one heavy and one light chain (HL), exchange with IgG4 antibodies of different specificities, resulting in the formation of bi-specific antibodies [15]. FAE has been demonstrated to occur in vivo $[25,26]$.

Structurally, the two half HL molecules are held together by covalent (hinge disulfide bonds) and non-covalent $\left(\mathrm{C}_{\mathrm{H}} 3-\mathrm{C}_{\mathrm{H}} 3\right)$ interactions. Two features, namely the core hinge sequence and residue 409 at the $\mathrm{C}_{\mathrm{H}} 3-\mathrm{C}_{\mathrm{H}} 3$ domain interface, which both weaken the interactions between the two half $\mathrm{HL}$ molecules, are responsible for the ability of IgG4 to undergo FAE (Fig. 1a).

In IgG1, which does not undergo FAE, residues 226-229 in the core hinge have a Cysteine-Proline-Proline-Cysteine (CPPC) sequence motif. On the other hand, the IgG4 core hinge has a Cysteine-Proline-Serine-Cysteine (CPSC) motif. The IgG4 core hinge is believed to be more flexible, promoting the formation of intra-heavy chain disulfide bonds, Thus, two hinge isomers are possible, one with the typical interheavy chain disulfide bonds (covalently linked half molecules), and the other with intra-heavy chain disulfide bonds (non-covalently linked half molecules) [26, 27] (Fig. 1a). The S228P mutation, which renders the IgG4 core hinge more IgG1-like, abolishes the formation of intra-chain disulfide bond isomers and abrogates FAE in vitro and in vivo [26, 27].

Additionally, the $\operatorname{IgG} 4 \mathrm{C}_{\mathrm{H}} 3$ domain differs from the $\mathrm{IgG} 1$ $\mathrm{C}_{\mathrm{H}} 3$ domain in that lysine 409 in IgG1 is substituted for arginine in IgG4 (Fig. 1a). Residue 409 is located at the interface between the $\mathrm{C}_{\mathrm{H}} 3$ domain dimer. Arg409 disrupts the interdomain network of water-mediated hydrogen bonds that is conserved in IgG1 and weakens the non-covalent interaction between the $\mathrm{C}_{\mathrm{H}} 3$ domains $[28,29 \bullet \bullet$.

A direct consequence of Fab-arm exchange is the production of IgG4 antibodies with random dual specificity, unable to crosslink identical antigens and therefore perhaps unable to form large IC against a specific target. For this reason, such IgG4 molecules may be defined as functionally monovalent [30, 31].

A different interpretation of FAE may be that bispecificity, the ability to bind two antigens, is a property that might increase the avidity of the antibody if these antigens are proximally located on target cells [32]. If bi-specific IgG4 could crosslink two different antigens, for instance on the surface of a tumor cell, the effects of these interactions are far from clear, and these interactions might promote or restrict target cell signaling and growth. 


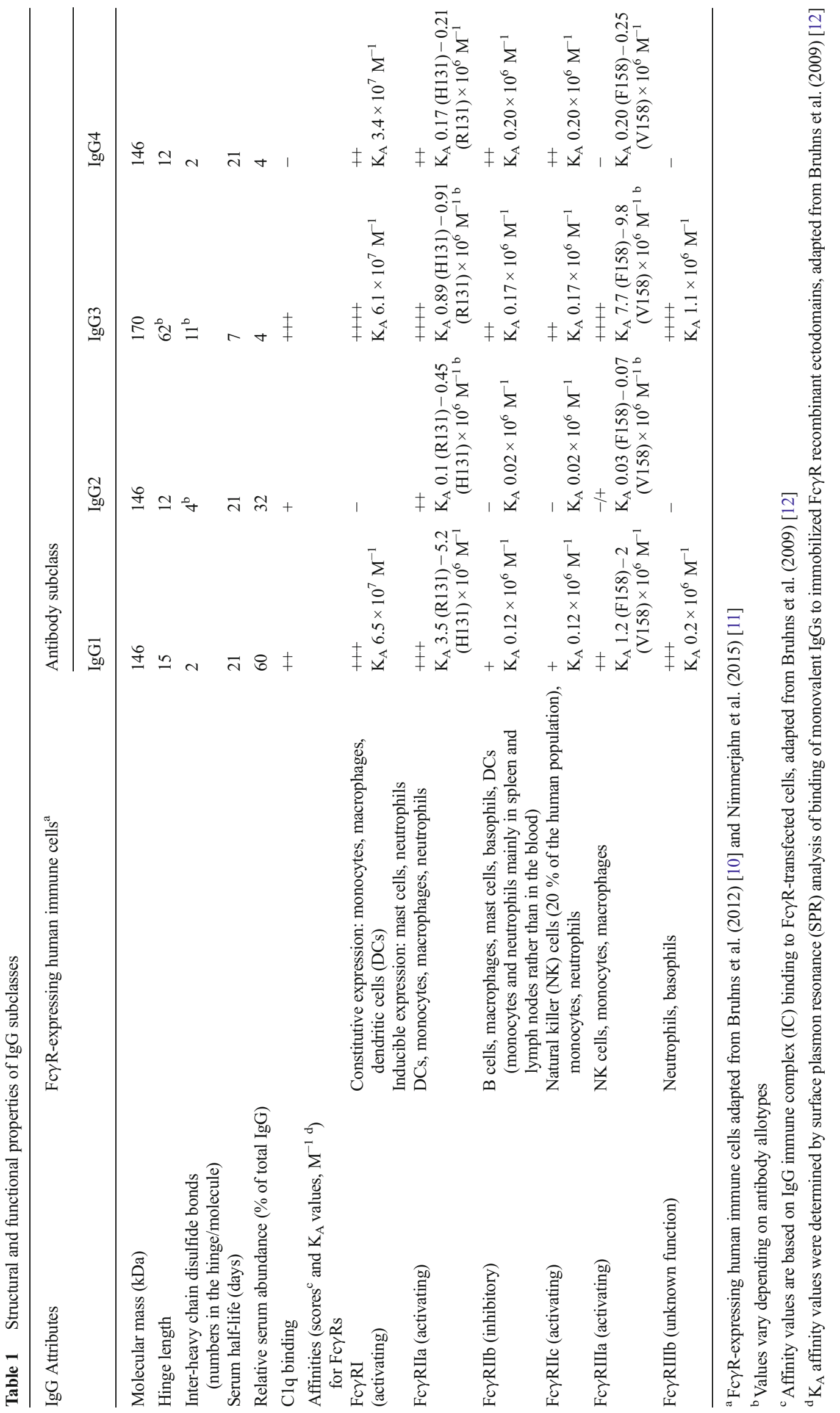




\section{A Temporal Model for Isotype Switching: Potential Implications for Higher Antigen Affinities for IgG4}

An analysis of almost 1000 VDJ sequences extracted from B cells of individuals living in an area of endemic parasitism showed a positive correlation between the number of mutations somatic hypermutation (SHM) and the distance of the specific $\mathrm{C} \gamma$ gene from the VDJ region in the heavy chain locus. The $\mathrm{C} \gamma 4$ locus is the last of the $\mathrm{IgG}$ subclasses on chromosome $14[33 \cdot \bullet]$. The authors proposed a temporal model, where CSR occurred sequentially from IgM to IgG3 then to IgG1, to IgG2, and finally to IgG4, with the implication that class-switched IgG4 B cells would be the last to exit from germinal centers. Since AID is involved both in CSR and SHM, B cells would also accumulate mutations in the VDJ region, leading to the production of antibodies with higher affinity (affinity matured) [32]. Most activating immune responses induce the rapid production of $\operatorname{IgG} 3$ and $\operatorname{IgG} 1$, but not of the other isotypes, possibly due to the rapid elimination of the antigen-expressing targets. However, if the antigen persists, $\mathrm{B}$ cells continue to be activated in the germinal centers and undergo sequential CSR to IgG2 and IgG4.

Notably, the $\mathrm{C} \gamma$ position on heavy chain locus and therefore the extent of SHM, also positively correlate with antibody effector functions (lower ability to activate complement and Fc $\gamma$ Rs for IgG2 and IgG4). This could be interpreted as a mechanism of self-regulation by the immune system to avoid self-damage in response to a chronic antigenic stimulus. According to the CSR temporal model, IgG4 has higher affinity for antigen compared to IgG1 or IgG3, while it also has poor capacity to activate complement and Fc $\gamma$ Rs. Evidence to support this model exists in the context of allergy [34] and of endemic parasitism $[32,33 \bullet \bullet$.

In cancer, high-affinity tumor-specific IgG4 could compete with IgG1 for the binding to tumor-associated antigens. Since IgG4 has lower ability to trigger effector functions compared to IgG1, this competition results in reduced antibodymediated effector functions and escape from the immune surveillance.

\section{Evidence for an IgG4 Bias in Some Tumors}

IgG4 is usually the least-represented $\operatorname{IgG}$ subclass in human serum, comprising less than $4 \%$ of the total $\mathrm{IgG}$, but high IgG4 levels can occur in particular conditions, usually following repeated or chronic exposure to an antigen. Elevated levels of IgG4 in tissues and in serum are associated with inflammation in a range of chronic pathological conditions, such as rheumatoid arthritis [35], IgG4-related diseases (IgG4-RD) [36], and pemphigus vulgaris [37]. Elevated levels of IgG4 are also associated with immune tolerance under conditions of chronic exposure to a specific antigen, such as tolerance to bee venom in beekeepers [38•] or reduced allergic symptoms after allergen-specific immunotherapy in atopic individuals $[14,39]$.

IgG4 responses have also been reported in different cancers such as melanoma $[40,41 \bullet \bullet, 42 \bullet \cdot]$, extrahepatic cholangiocarcinoma [43, 44], pancreatic cancer [45], and glioblastoma $[46 \bullet \bullet$.

Tumor lesions are pathological conditions which present features resembling chronic inflammation. Some of these features may be (a) formation of tertiary lymphoid structures, shown to contain functional germinal centers [47•] where antigen-driven antibody responses may occur $[48,49]$ and (b) infiltration of M2-type macrophages and $\mathrm{Foxp}^{+}{ }^{+}$regulatory T cells (Treg cells). IgG4 antibodies and $\mathrm{IgG}_{4}^{+} \mathrm{B}$ cells were detected together with Tregs in the tumor microenvironment of pancreatic cancer, cholangiocarcinoma [50], and melanoma lesions $[41 \bullet \cdot, 51]$. These tumor types were also characterized by Th2-biased environments with local expression of IL-10, IL-4, VEGF [41••], and TGF- $\beta$ [50], mediators known to trigger B cells to produce IgG4 (Fig. 1b). IgG4 was found to positively correlate with Tregs and to negatively correlate with cytotoxic T lymphocytes [50], supporting its involvement of immune tolerance in cancer. Furthermore, ex vivo studies suggested that melanoma and B cell cross-talk can trigger elevated expression of IL-10 and VEGF, inducing B cells to produce IgG4 $[41 \bullet \cdot$. Several carcinomas and cancer cell lines are found to produce IL-10 and FoxP3 [52], indicating that tumors may promote a biased Th2 response which supports $\operatorname{IgG} 4$, re-educating host immune responses and escaping the immune clearance. Consistent with this, elevated serum IgG4 levels have been associated with poorer prognosis in biliary

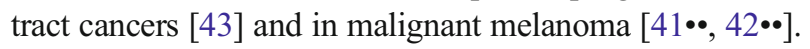

Whether any tumor-associated IgG4 antibodies are tumor reactive is still unclear, although early evidence suggests this may be true in malignant melanoma $[41 \cdot \bullet]$ and glioblastoma [46••]. Supernatants from ex vivo cultured B cells, isolated from melanoma patient blood and lesions, showed reactivity against melanoma cells in a cell-based ELISA [53], even if further analysis will be required to assess the specificity for tumor-associated antigens and exclude an allo-reactivity. Furthermore, tumor-exosome-reactive IgG4 and IgG2 antibodies were found in sera from glioblastoma patients [46••]. In other diseases, such as rheumatoid arthritis, IgG antibodies, including IgG4, were found to be specific for citrullinated fibrin and used as a serological marker [54]. On the other hand, in diseases such as IgG4-RD, IgG4 antibodies are usually found to be unspecific to disease-associated or auto-antigens [36]. Furthermore, only a small proportion of circulating IgG4 antibodies has been shown to recognize the specific allergen in atopic patients following allergen immunotherapy [55]. Thus, additional research would be required to ascertain the tumor reactivity and antigen specificity of tumor-associated IgG4 in patients with cancer. 


\section{IgG4 Anti-inflammatory Properties: Blockade of IgG1-Mediated Effector Functions in Some Disease Settings Including Cancer}

Evidence in different disease settings points to the ability of IgG4 to impair the effector functions of other immunoglobulins such as IgG1. In an in vivo model of myasthenia gravis, it was shown that IgG4 prevented IgG1-mediated internalization and degradation of acetylcholine receptors (AchRs) [25]. In human melanoma xenograft models in mice, partly reconstituted with human immune effector cells, tumor antigen-specific IgG4 could inhibit IgG1-mediated restriction of subcutaneous tumor growth $[41 \bullet \cdot]$.

IgG4 could exert its inhibitory functions binding through the Fab (tumor-specific IgG4) or binding through the Fc (unspecific IgG4). The potential mechanisms by which IgG4 can interfere with the immune activating functions of $\mathrm{IgG1}$ and of other class antibodies such as IgE are discussed below.

\section{IgG4 Competes with IgG1 for the Binding to the Antigen but Has Poor Ability to Trigger Effector Functions}

The affinity of IgG4 for Fc $\gamma \mathrm{RI}$ is of the same order of magnitude as that of IgG1, while its affinities for Fc $\gamma$ RIIa and Fc $\gamma$ RIIIa are much lower than those of IgG1. Fc $\gamma$ Rs expressed on immune effector cells are engaged by antibodies to trigger antibody-dependent cellular phagocytosis (ADCP) and antibody-dependent cellular cytotoxicity (ADCC). Fc $\gamma$ RIIa expressed on macrophages and phagocytes is involved in ADCP [56], while Fc $\gamma$ RIIIa is expressed on NK cells and plays a crucial role in ADCC [57]. For this reason, even if IgG4 is able to bind Fc $\gamma \mathrm{RI}$, the poor affinity to the other activating receptors may result in lower potency to mediate ADCC [58-61], and ADCP compared to IgG1. In general, IgG4 effector function could depend on the relative expression of Fc $\gamma$ Rs on the effector cells. Furthermore, unlike $\mathrm{IgG1}, \mathrm{IgG} 4$ is not able to trigger complement-dependent cytotoxicity (CDC) [59].

In a scenario where IgG4 competes with IgG1 for the binding to the antigen, the poor effector function of IgG4 could result in the blocking of the potential IgG1-mediated effect (Fig. 1b).

There are mainly two mechanisms by which IgG4 could compete with IgG1 for the binding to the tumor. Firstly, according to CSR temporal model, IgG4 antibodies developed in the lesion should have higher affinity for the target antigen compared with $\operatorname{IgG1}$, therefore competing for the binding to the tumor cells. The second is based on the theory that FAE is a mechanism that could, in certain conditions, increase IgG4 avidity to the antigen. Bi-specific IgG4 antibodies, able to simultaneously bind to the same or related antigens on target cells, are unlikely if Fab-arm exchange occurs in the blood stream with other IgG4 antibodies of unrelated specificity
[25]. However, this might occur if clonally related antibodies against the same antigen or antibodies against different antigens on the same target cells co-localize at a site of inflammation [32], such as in tumor microenvironments.

\section{High-affinity IgG4 Can Take Part in IgG1 IC Co-engaging Fc $\gamma$ RIIb with Activating Fe $\gamma$ Rs}

Another possible mechanism of action of IgG4 could be mediated through the binding to the inhibitory receptor Fc $\gamma \mathrm{RIIb}$. There is evidence that IgG4 can bind Fc $\gamma$ RIIb with higher affinity than other IgG subclasses (Table 1) [12]. Fc $\gamma$ RIIb is known to play a crucial role in regulating both innate (macrophage, mast cell, and basophil activation) and adaptive immunity (DC activation and antigen cross-presentation). It is also involved in B cell and plasma cell fate during the immune response [62]. Since Fc $\gamma$ RIIb is able to exert its inhibitory action only if co-engaged with activating Fc $\gamma$ Rs [25], it has been speculated that high-affinity IgG4 could form ICs together with other antibodies, such as IgG1, and co-engage both Fc $\gamma$ RIIb and activating Fc $\gamma$ Rs, thus dampening Fc $\gamma$ Rmediated processes (Fig. 1b). According to this hypothesis, IgG4 might be able to exert an inhibitory effect even if its concentration is lower than IgG1 [32].

\section{IgG4 Can Bind IgG1 via Fc-Fc Interactions}

IgG4 has been shown to bind other IgGs, in particular IgG1, via $\mathrm{Fc}-\mathrm{Fc}$ interactions $[63,64 \bullet \cdot]$. Two crystal structures of IgG4-Fc show two interfaces for $\mathrm{Fc}-\mathrm{Fc}$ interactions localized in IgG4 $\mathrm{C}_{\mathrm{H}} 2$ and $\mathrm{C}_{\mathrm{H}} 3$ domains. Residues from these two interfaces belong to a consensus binding site for Fc-binding proteins such as neonatal $\mathrm{Fc}$ receptor (FcRn), TRIM21 [65], rheumatoid factor, staphylococcal protein A, streptococcal protein G, and the Herpes simplex virus type 1 (HSV-1) gEgI receptor [66], and some residues also belong to aggregation-prone motifs [67]. The Fc-Fc interactions observed in the IgG4-Fc crystal structures may provide a model for the tendency of IgG4 to aggregate [24••]. Indeed, a study of therapeutic monoclonal antibodies showed that IgG4 has a higher tendency to aggregate than IgG1 [68].

A rheumatoid factor-like activity of IgG4 was observed first in rheumatoid arthritis $[69,70]$ and recently in autoimmune pancreatitis [71]. IgG4-Fc and not Fab was found to bind the heavy chain of all IgG1 subclasses [71]. Furthermore, $\mathrm{Fc}-\mathrm{Fc}$ interaction was demonstrated between $\mathrm{IgG} 4$ and conformationally altered IgG4 or IgG1 immobilized on a solid-phase [63]. It was furthermore shown that IgG4 Fc-Fc interactions require partial dissociation of the $\operatorname{IgG}$ heavy chains [64.•*]. The authors hypothesized that IgG4 could act as a scavenger, by binding to IgG fragments and preventing their unfolding and formation of aggregates [64••]. 
Tumor microenvironments are rich in proteases such as matrix metalloproteases (MMP), which support extracellular matrix degradation, tissue remodeling, and promotion of cancer cell metastasis. An additional effect of these enzymes may be to partly dissociate or cleave host-produced or therapeutic antibodies [72]. An association between an inflammatory environment and the cleavage of autoantibodies was also found in rheumatoid arthritis [73]. In vitro studies showed that microbial origin and tumor-related proteases are also able to cleave IgG1 in a conserved region at the lower hinge/ $\mathrm{C}_{\mathrm{H}} 2$ interface. Full cleavage to $\mathrm{F}\left(\mathrm{ab}^{\prime}\right)_{2}$ fragments is preceded by an intermediate with one intact heavy chain [74]. The same authors reported cleaved antibodies in breast cancer tumor extracts and suggested that cleaved IgG antibodies are likely present in tumor microenvironments. The cleaved antibodies have impaired FcR binding and effector functions but comparable antigenbinding capacity to that of intact antibodies. These damaged antibodies could therefore compete for the binding to the antigen and block the functional effects of undamaged IgGs [74], suggesting that proteolytic activity in tumor microenvironments could impair IgGs as a possible mechanism of tumor escape from host immune surveillance [72, 74].

In the proteolytic conditions of a tumor microenvironment, with cleaved IgG1 antibodies bound to tumor antigens, the cleavage of one of the heavy chains at the junction between the lower hinge and the $\mathrm{C}_{\mathrm{H}} 2$ domain may cause a partial dissociation of the cleaved heavy chain from the rest of the antibody. The partly dissociated IgG1 could facilitate the binding of IgG4-Fc resulting in the blockade, via Fc-Fc interactions, of single-chain cleaved IgG1 on the surface of tumor cells (Fig. 1b). This would probably require a high local concentration of IgG4 to overcome the affinity of the IgG1-Fc region for Fcy receptors. However, the concentration of immunoglobulins in tumors is currently unknown. Fc-Fc mediated interactions could potentially interfere with IgG1mediated effector functions or result in intracellular uptake and clearance of the target from the tumor cell surface.

\section{Implications of Employing IgG4 Subclass Antibodies in Cancer Immunotherapy}

\section{Passive Immunotherapy}

$\operatorname{IgG} 4$, together with $\operatorname{IgG} 2$, is the preferential subclass in the design of therapeutic antibodies, when the recruitment of the immune cells is undesired (receptor-blocking antibodies) or unnecessary (payload delivery antibodies) [75]. Therapeutic IgG4s can undergo FAE with endogenous IgG4. Depending on the mechanism of action of each specific therapeutic antibody, hinge stabilization (S228P mutation) could be a design consideration to prevent FAE in vivo [26].

IgG4 is generally considered an anti-inflammatory antibody due to its functionally monovalent properties, its poor ability to bind $\mathrm{C} 1 \mathrm{q}$ and the activating low-affinity Fc $\gamma$ Rs. Nevertheless, IgG4 binds Fc $\gamma R$ I with a $K_{A}$ of the same order of magnitude as IgG1 and IgG3, and the inhibitory Fc $\gamma$ RIIb receptor with higher affinity than the other subclasses [12, 76]. Thus in principle, it may be able to trigger effector functions. To eliminate any residual effector functions, therapeutic IgG4 antibodies can be engineered with mutations (such as L235E) that abrogate Fc $\gamma \mathrm{R}$ interactions [77, 78].

The overall anti-inflammatory activity of $\operatorname{IgG} 4 \mathrm{~s}$, despite their affinity for Fc $\gamma$ RI, could be related to their functional monovalency [15]. Therapeutic IgG4s carrying the S228P mutation are monospecific due to their inability to undergo FAE and would be able to crosslink antigens and to form small or large ICs. Large IgG4-ICs are able to bind the activating low-affinity Fc $\gamma$ Rs [79]. For this reason, during the design of IgG4 therapeutic antibodies, it may be important to incorporate both mutations that stabilize the hinge and those that completely abrogate Fc $\gamma$ receptor binding.

\section{Active Immunotherapy}

Triggering a patient response against cancer may be a desirable feature of active cancer immunotherapy. The emerging field known as AllergoOncology includes the use of IgE antibodies and antibody responses in cancer therapy [80]. IgE class switching may occur in a relatively naïve IgM-secreting B cell (direct route) or in an isotype-switched IgG4-expressing B cell (indirect route) [81]. In a clinical context, where the tumor lesion is infiltrated with $\mathrm{IgG}_{4}^{+} \mathrm{B}$ cells expressing highaffinity tumor antigen-specific IgG4s [41••], a valid tool for active immunotherapy could be the implementation of immunization approaches that support tumor-localized isotype switching from IgG4 to more potent IgE antibodies, via the indirect route. The result may be in situ production, of tumor antigen-specific $\operatorname{IgE}$ with high affinity for tumor targets that could mediate potent ADCC and ADCP against tumor cells and restrict tumor progression. Alternative approaches such as treatment with engineered IgE antibodies against cancer antigens may activate effector cells by signaling through IgE Fc receptors, as a means of bypassing IgG4mediated Fc blockade mechanisms. In the last decade, mounting evidence supports the idea of engineering $\operatorname{IgE}$ antibodies and vaccination approaches that result in IgEbiased immune responses against cancer as powerful tools for cancer immunotherapy [82-85]. 


\section{Conclusion}

The structural and functional attributes of $\mathrm{IgG} 4$ described here render it unique among the IgG subclasses. Its ability to undergo FAE may be only partly responsible for its low affinity for activating receptors expressed on immune effector cells and consequently low capacity to engage these cells to trigger ADCP and ADCC and also for its poor ability to bind C1q and fix complement. IgG4 is considered an antibody with low immunoactivatory properties, and it is a suitable subclass for the design of therapeutic antibodies when effector functions are not desirable. However, a better understanding of its properties and functions in vivo is still required to inform the design and optimization of IgG4-based therapeutic antibodies. Reports of IgG4 antibodies and IgG4+ B cells in different cancers suggest the involvement of IgG4 in tumor escape from immune surveillance through a number of potential mechanisms, including IgG4 blockade of IgG1-mediated effector functions. However, IgG4 and its roles in cancer inflammation remain unclear. Dissecting the crosstalk between cancer and humoral immunity and the conditions that can promote IgG4-biased "regulatory" responses can inform the design of novel therapeutic antibodies with improved immune activatory and effector functions and reduced susceptibility to tumor-associated immune blockade.

\begin{abstract}
Acknowledgments The research was supported by the National Institute for Health Research (NIHR) Biomedical Research Centre based at Guy's and St. Thomas' NHS Foundation Trust and King's College London. The views expressed are those of the author(s) and not necessarily those of the NHS, the NIHR, or the Department of Health. Anna M. Davies is funded by the Medical Research Council, UK (G1100090). The authors acknowledge support by Cancer Research UK (C30122/ A11527; C30122/A15774); the Medical Research Council (MR/ L023091/1); CR UK/NIHR in England/DoH for Scotland, Wales, and Northern Ireland Experimental Cancer Medicine Centre (C10355/ A15587).
\end{abstract}

\section{Compliance with Ethical Standards}

Conflict of Interest The authors declare that they have no competing interests.

Human and Animal Rights and Informed Consent This article does not contain any studies with human or animal subjects performed by any of the authors.

Open Access This article is distributed under the terms of the Creative Commons Attribution 4.0 International License (http:// creativecommons.org/licenses/by/4.0/), which permits unrestricted use, distribution, and reproduction in any medium, provided you give appropriate credit to the original author(s) and the source, provide a link to the Creative Commons license, and indicate if changes were made.

\section{References}

Papers of particular interest, published recently, have been highlighted as:

- Of importance

• Of major importance

1. Schur PH. IgG subclasses. A historical perspective. Monogr Allergy. 1988;23:1-11.

2. Vidarsson G, Dekkers G, Rispens T. IgG subclasses and allotypes: from structure to effector functions. Front Immunol. 2014;5:520. Up-to-date review of IgG subclasse structure and their relationship to antibody effector functions.

3. Lefranc MP. WHO-IUIS Nomenclature Subcommittee for immunoglobulins and $\mathrm{T}$ cell receptors report. Immunogenetics. 2007;59(12):899-902.

4. Xu Z, Zan H, Pone EJ, Mai T, Casali P. Immunoglobulin classswitch DNA recombination: induction, targeting and beyond. Nat Rev Immunol. 2012;12(7):517-31.

5. Agresti A, Vercelli D. Analysis of gamma4 germline transcription in human B cells. Int Arch Allergy Immunol. 1999;118(2-4):27981.

6. Punnonen J, Aversa G, Cocks BG, McKenzie AN, Menon S, Zurawski G, et al. Interleukin 13 induces interleukin 4independent IgG4 and IgE synthesis and CD23 expression by human B cells. Proc Natl Acad Sci U S A. 1993;90(8):3730-4.

7. Akdis CA, Akdis M. Mechanisms of immune tolerance to allergens: role of IL-10 and Tregs. J Clin Invest. 2014;124(11):4678-80.

8. de Boer BA, Kruize YC, Rotmans PJ, Yazdanbakhsh M. Interleukin-12 suppresses immunoglobulin E production but enhances immunoglobulin $\mathrm{G} 4$ production by human peripheral blood mononuclear cells. Infect Immun. 1997;65(3):1122-5.

9. Maehara T, Moriyama M, Nakashima H, Miyake K, Hayashida JN, Tanaka A, et al. Interleukin-21 contributes to germinal centre formation and immunoglobulin G4 production in IgG4-related dacryoadenitis and sialoadenitis, so-called Mikulicz's disease. Ann Rheum Dis. 2012;71(12):2011-9.

10. Bruhns P. Properties of mouse and human $\operatorname{IgG}$ receptors and their contribution to disease models. Blood. 2012;119(24):5640-9.

11. Nimmerjahn F, Gordan S, Lux A. Fc $\gamma$ R dependent mechanisms of cytotoxic, agonistic, and neutralizing antibody activities. Trends Immunol. 2015;36(6):325-36.

12. Bruhns P, Iannascoli B, England P, Mancardi DA, Fernandez N, Jorieux S, et al. Specificity and affinity of human Fcgamma receptors and their polymorphic variants for human IgG subclasses. Blood. 2009;113(16):3716-25.

13. Su K, Wu J, Edberg JC, McKenzie SE, Kimberly RP. Genomic organization of classical human low-affinity Fcgamma receptor genes. Genes Immun. 2002;3 Suppl 1:S51-6.

14. Aalberse RC, Stapel SO, Schuurman J, Rispens T. Immunoglobulin G4: an odd antibody. Clin Exp Allergy. 2009;39(4):469-77.

15. Aalberse RC, Schuurman J. IgG4 breaking the rules. Immunology. 2002;105(1):9-19.

16. Edelman GM, Cunningham BA, Gall WE, Gottlieb PD, Rutishauser U, Waxdal MJ. The covalent structure of an entire gammaG immunoglobulin molecule. Proc Natl Acad Sci U S A. 1969;63(1):78-85.

17. Roux KH, Strelets L, Michaelsen TE. Flexibility of human IgG subclasses. J Immunol. 1997;159(7):3372-82.

18. Rayner LE, Hui GK, Gor J, Heenan RK, Dalby PA, Perkins SJ. The Fab conformations in the solution structure of human immunoglobulin G4 (IgG4) restrict access to its $\mathrm{Fc}$ region: implications for functional activity. J Biol Chem. 2014;289(30):20740-56. 
19. Tan LK, Shopes RJ, Oi VT, Morrison SL. Influence of the hinge region on complement activation, $\mathrm{Clq}$ binding, and segmental flexibility in chimeric human immunoglobulins. Proc Natl Acad Sci U S A. 1990;87(1):162-6.

20. Sondermann P, Huber R, Oosthuizen V, Jacob U. The 3.2-A crystal structure of the human IgG1 Fc fragment-Fc gammaRIII complex. Nature. 2000;406(6793):267-73.

21. Radaev S, Motyka S, Fridman WH, Sautes-Fridman C, Sun PD. The structure of a human type III Fcgamma receptor in complex with Fc. J Biol Chem. 2001;276(19):16469-77.

22. Tao MH, Smith RI, Morrison SL. Structural features of human immunoglobulin $\mathrm{G}$ that determine isotype-specific differences in complement activation. J Exp Med. 1993;178(2):661-7.

23. Idusogie EE, Presta LG, Gazzano-Santoro H, Totpal K, Wong PY, Ultsch $\mathrm{M}$, et al. Mapping of the $\mathrm{C} 1 \mathrm{q}$ binding site on rituxan, a chimeric antibody with a human IgG1 Fc. J Immunol. 2000;164(8):4178-84.

24.• Davies AM, Rispens T, Ooijevaar-de Heer P, Gould HJ, Jefferis R, Aalberse RC, et al. Structural determinants of unique properties of human IgG4-Fc. J Mol Biol. 2014;426(3):630-44. Study showing the structural features in the hinge region and the $\mathrm{CH} 2$ and CH3 domains that make IgG4 structurally unique.

25. van der Neut Kolfschoten M, Schuurman J, Losen M, Bleeker WK, Martínez-Martínez P, Vermeulen E, et al. Anti-inflammatory activity of human IgG4 antibodies by dynamic Fab arm exchange. Science. 2007;317(5844):1554-7.

26. Labrijn AF, Buijsse AO, van den Bremer ET, Verwilligen AY, Bleeker WK, Thorpe SJ, et al. Therapeutic IgG4 antibodies engage in Fab-arm exchange with endogenous human IgG4 in vivo. Nat Biotechnol. 2009;27(8):767-71

27. Angal S, King DJ, Bodmer MW, Turner A, Lawson AD, Roberts G, et al. A single amino acid substitution abolishes the heterogeneity of chimeric mouse/human (IgG4) antibody. Mol Immunol. 1993;30(1):105-8

28. Labrijn AF, Rispens T, Meesters J, Rose RJ, den Bleker TH, Loverix S, et al. Species-specific determinants in the $\mathrm{IgG}$ CH3 domain enable Fab-arm exchange by affecting the noncovalent CH3-CH3 interaction strength. J Immunol. 2011;187(6):3238-46.

29.• Davies AM, Rispens T, den Bleker TH, McDonnell JM, Gould HJ, Aalberse RC, et al. Crystal structure of the human IgG4 $\mathrm{C}(\mathrm{H}) 3$ dimer reveals the role of Arg409 in the mechanism of Fab-arm exchange. Mol Immunol. 2013;54(1):1-7. Demonstration of the role of Arg409 in the mechanism of IgG4 FAE.

30. van der Zee JS, van Swieten P, Aalberse RC. Serologic aspects of IgG4 antibodies. II. IgG4 antibodies form small, nonprecipitating immune complexes due to functional monovalency. J Immunol. 1986;137(11):3566-71.

31. Schuurman J, Van Ree R, Perdok GJ, Van Doorn HR, Tan KY, Aalberse RC. Normal human immunoglobulin G4 is bispecific: it has two different antigen-combining sites. Immunology. 1999;97(4):693-8

32. Collins AM, Jackson KJ. A temporal model of human IgE and IgG antibody function. Front Immunol. 2013;4:235.

33.• Jackson KJ, Wang Y, Collins AM. Human immunoglobulin classes and subclasses show variability in VDJ gene mutation levels. Immunol Cell Biol. 2014;92(8):729-33. Study confirming the positive correlation between SHM, and thus affinity maturation, with the distance of the gamma chain genes in the heavy chain locus, in support of the temporal model of CSR.

34. Rogosch T, Kerzel S, Dey F, Wagner JJ, Zhang Z, Maier RF, et al. IgG4 and IgE transcripts in childhood allergic asthma reflect divergent antigen-driven selection. J Immunol. 2014;193(12):5801-8.

35. Chen LF, Mo YQ, Ma JD, Luo L, Zheng DH, Dai L. Elevated serum IgG4 defines specific clinical phenotype of rheumatoid arthritis. Mediat Inflamm. 2014;2014:635293.
36. Fragoulis GE, Moutsopoulos HM. IgG4 syndrome: old disease, new perspective. J Rheumatol. 2010;37(7):1369-70.

37. Futei Y, Amagai M, Ishii K, Kuroda-Kinoshita K, Ohya K, Nishikawa T. Predominant IgG4 subclass in autoantibodies of pemphigus vulgaris and foliaceus. J Dermatol Sci. 2001;26(1):55-61.

38. Varga EM, Kausar F, Aberer W, Zach M, Eber E, Durham SR, et al. Tolerant beekeepers display venom-specific functional IgG4 antibodies in the absence of specific IgE. J Allergy Clin Immunol. 2013;131(5):1419-21. Study confirming the association of IgG4 and immune tolerance after chronic exposure to an antigen.

39. Shamji MH, Ljørring C, Francis JN, Calderon MA, Larché M, Kimber I, et al. Functional rather than immunoreactive levels of IgG4 correlate closely with clinical response to grass pollen immunotherapy. Allergy. 2012;67(2):217-26.

40. Daveau M, Pavie-Fischer J, Rivat L, Rivat C, Ropartz C, Peter HH, et al. IgG4 subclass in malignant melanoma. J Natl Cancer Inst. 1977;58(2):189-92.

41.• Karagiannis P, Gilbert AE, Josephs DH, Ali N, Dodev T, Saul L, et al. IgG4 subclass antibodies impair antitumor immunity in melanoma. J Clin Invest. 2013;123(4):1457-74. Study showing evidence of IgG4-bias in melanoma and investigating the mechanisms of action of IgG4 in the blockade of IgG1-mediated effector functions against cancer.

42.• Karagiannis P, Villanova F, Josephs DH, Correa I, Van Hemelrijck $\mathrm{M}$, Hobbs $\mathrm{C}$, et al. Elevated IgG4 in patient circulation is associated with the risk of disease progression in melanoma. Oncoimmunology. 2015;4(11):e1032492. Study showing the importance of elevated serum levels of IgG4 as a negative prognostic indicator in melanoma.

43. Harada K, Shimoda S, Kimura Y, Sato Y, Ikeda H, Igarashi S, et al. Significance of immunoglobulin G4 (IgG4)-positive cells in extrahepatic cholangiocarcinoma: molecular mechanism of IgG4 reaction in cancer tissue. Hepatology. 2012;56(1):157-64.

44. Harada K, Nakanuma Y. Cholangiocarcinoma with respect to IgG4 reaction. Int J Hepatol. 2014;2014:803876.

45. Raina A, Krasinskas AM, Greer JB, Lamb J, Fink E, Moser AJ, et al. Serum immunoglobulin $\mathrm{G}$ fraction 4 levels in pancreatic cancer: elevations not associated with autoimmune pancreatitis. Arch Pathol Lab Med. 2008;132(1):48-53.

46.• Harshyne LA, Nasca BJ, Kenyon LC, Andrews DW, Hooper DC. Serum exosomes and cytokines promote a T-helper cell type 2 environment in the peripheral blood of glioblastoma patients. Neuro Oncol. 2015. Study showing evidence of a link between elevated serum levels of IgG4 and Th2-biased immunity in the circulation of patients with glioblastoma.

47. Egbuniwe IU, Karagiannis SN, Nestle FO, Lacy KE. Revisiting the role of B cells in skin immune surveillance. Trends Immunol. 2015;36(2):102-11. Up-to-date review of the role of B cells in skin immune surveillance, including skin cancer surveillance.

48. Cipponi A, Mercier M, Seremet T, Baurain JF, Theate I, van den Oord J, et al. Neogenesis of lymphoid structures and antibody responses occur in human melanoma metastases. Cancer Res. 2012;72(16):3997-4007.

49. Coppola D, Nebozhyn M, Khalil F, Dai H, Yeatman T, Loboda A, et al. Unique ectopic lymph node-like structures present in human primary colorectal carcinoma are identified by immune gene array profiling. Am J Pathol. 2011;179(1):37-45.

50. Kimura Y, Harada K, Nakanuma Y. Pathologic significance of immunoglobulin G4-positive plasma cells in extrahepatic cholangiocarcinoma. Hum Pathol. 2012;43(12):2149-56.

51. Karagiannis P, Gilbert AE, Nestle FO, Karagiannis SN. IgG4 antibodies and cancer-associated inflammation: insights into a novel mechanism of immune escape. Oncoimmunology. 2013;2(7): e24889. 
52. Hinz S, Pagerols-Raluy L, Oberg HH, Ammerpohl O, Grüssel S, Sipos B, et al. Foxp3 expression in pancreatic carcinoma cells as a novel mechanism of immune evasion in cancer. Cancer Res. 2007;67(17):8344-50.

53. Gilbert AE, Karagiannis P, Dodev T, Koers A, Lacy K, Josephs DH, et al. Monitoring the systemic human memory B cell compartment of melanoma patients for anti-tumor IgG antibodies. PLoS One. 2011;6(4):e19330.

54. Chapuy-Regaud S, Nogueira L, Clavel C, Sebbag M, Vincent C, Serre G. IgG subclass distribution of the rheumatoid arthritisspecific autoantibodies to citrullinated fibrin. Clin Exp Immunol. 2005;139(3):542-50.

55. James LK, Bowen H, Calvert RA, Dodev TS, Shamji MH, Beavil AJ, et al. Allergen specificity of $\operatorname{IgG}(4)$-expressing B cells in patients with grass pollen allergy undergoing immunotherapy. J Allergy Clin Immunol. 2012;130(3):663-70.e3.

56. Richards JO, Karki S, Lazar GA, Chen H, Dang W, Desjarlais JR. Optimization of antibody binding to FcgammaRIIa enhances macrophage phagocytosis of tumor cells. Mol Cancer Ther. 2008;7(8): 2517-27.

57. Seidel UJ, Schlegel P, Lang P. Natural killer cell mediated antibodydependent cellular cytotoxicity in tumor immunotherapy with therapeutic antibodies. Front Immunol. 2013;4:76.

58. Warncke M, Calzascia T, Coulot M, Balke N, Touil R, Kolbinger F, et al. Different adaptations of IgG effector function in human and nonhuman primates and implications for therapeutic antibody treatment. J Immunol. 2012;188(9):4405-11.

59. Niwa R, Natsume A, Uehara A, Wakitani M, Iida S, Uchida K, et al. IgG subclass-independent improvement of antibody-dependent cellular cytotoxicity by fucose removal from Asn297-linked oligosaccharides. J Immunol Methods. 2005;306(1-2):151-60.

60. Brüggemann M, Williams GT, Bindon CI, Clark MR, Walker MR, Jefferis R, et al. Comparison of the effector functions of human immunoglobulins using a matched set of chimeric antibodies. J Exp Med. 1987;166(5):1351-61.

61. Overdijk MB, Verploegen S, Ortiz Buijsse A, Vink T, Leusen JH, Bleeker WK, et al. Crosstalk between human IgG isotypes and murine effector cells. J Immunol. 2012;189(7):3430-8.

62. Nimmerjahn F, Ravetch JV. Fcgamma receptors as regulators of immune responses. Nat Rev Immunol. 2008;8(1):34-47.

63. Rispens T, Ooievaar-De Heer P, Vermeulen E, Schuurman J, van der Kolfschoten Neut M, Aalberse RC. Human IgG4 binds to IgG4 and conformationally altered $\mathrm{IgG} 1$ via $\mathrm{Fc}-\mathrm{Fc}$ interactions. J Immunol. 2009;182(7):4275-81.

64.• Rispens T, Meesters J, den Bleker TH, Ooijevaar-De Heer P, Schuurman J, Parren PW, et al. Fc-Fc interactions of human IgG4 require dissociation of heavy chains and are formed predominantly by the intra-chain hinge isomer. Mol Immunol. 2013;53(1-):35-42. Study showing the ability of IgG4 to form Fc-Fc interactions with other IgGs with partially dissociated heavy chains.

65. James LC, Keeble AH, Khan Z, Rhodes DA, Trowsdale J. Structural basis for PRYSPRY-mediated tripartite motif (TRIM) protein function. Proc Natl Acad Sci U S A. 2007;104(15):6200-5.

66. Sprague ER, Wang C, Baker D, Bjorkman PJ. Crystal structure of the HSV-1 Fc receptor bound to Fc reveals a mechanism for antibody bipolar bridging. PLoS Biol. 2006;4(6):e148.

67. Chennamsetty N, Helk B, Voynov V, Kayser V, Trout BL. Aggregation-prone motifs in human immunoglobulin G. J Mol Biol. 2009;391(2):404-13.

68. Ishikawa T, Ito T, Endo R, Nakagawa K, Sawa E, Wakamatsu K. Influence of $\mathrm{pH}$ on heat-induced aggregation and degradation of therapeutic monoclonal antibodies. Biol Pharm Bull. 2010;33(8): 1413-7.
69. Cohen PL, Cheek RL, Hadler JA, Yount WJ, Eisenberg RA. The subclass distribution of human IgG rheumatoid factor. J Immunol. 1987;139(5):1466-71.

70. Zack DJ, Stempniak M, Wong AL, Weisbart RH. Localization of an Fc-binding reactivity to the constant region of human IgG4. Implications for the pathogenesis of rheumatoid arthritis. J Immunol. 1995;155(10):5057-63.

71. Kawa S, Kitahara K, Hamano H, Ozaki Y, Arakura N, Yoshizawa $\mathrm{K}$, et al. A novel immunoglobulin-immunoglobulin interaction in autoimmunity. PLoS One. 2008;3(2):e1637.

72. Brezski RJ, Jordan RE. Cleavage of IgGs by proteases associated with invasive diseases: an evasion tactic against host immunity? MAbs. 2010;2(3):212-20.

73. van de Stadt LA, de Vrieze H, Derksen NI, Brouwer M, Wouters D, van Schaardenburg D, et al. Antibodies to IgG4 hinge can be found in rheumatoid arthritis patients during all stages of disease and may exacerbate chronic antibody-mediated inflammation. Arthritis Rheum. 2014;66(5):1133-40.

74. Brezski RJ, Vafa O, Petrone D, Tam SH, Powers G, Ryan MH, et al. Tumor-associated and microbial proteases compromise host IgG effector functions by a single cleavage proximal to the hinge. Proc Natl Acad Sci U S A. 2009;106(42):17864-9.

75. Labrijn AF, Aalberse RC, Schuurman J. When binding is enough: nonactivating antibody formats. Curr Opin Immunol. 2008;20(4): 479-85.

76. Armour KL, van de Winkel JG, Williamson LM, Clark MR. Differential binding to human FcgammaRIIa and FcgammaRIIb receptors by human IgG wildtype and mutant antibodies. Mol Immunol. 2003;40(9):585-93.

77. Reddy MP, Kinney CA, Chaikin MA, Payne A, Fishman-Lobell J, Tsui $\mathrm{P}$, et al. Elimination of Fc receptor-dependent effector functions of a modified IgG4 monoclonal antibody to human CD4. J Immunol. 2000;164(4):1925-33.

78. Newman R, Hariharan K, Reff M, Anderson DR, Braslawsky G, Santoro D, et al. Modification of the Fc region of a primatized IgG antibody to human CD4 retains its ability to modulate CD4 receptors but does not deplete CD4(+) T cells in chimpanzees. Clin Immunol. 2001;98(2):164-74.

79. Lux A, Yu X, Scanlan CN, Nimmerjahn F. Impact of immune complex size and glycosylation on IgG binding to human Fc $\gamma$ Rs. J Immunol. 2013;190(8):4315-23.

80. Josephs DH, Spicer JF, Karagiannis P, Gould HJ, Karagiannis SN. $\mathrm{IgE}$ immunotherapy: a novel concept with promise for the treatment of cancer. MAbs. 2014;6(1):54-72.

81. Aalberse RC, Platts-Mills TA. How do we avoid developing allergy: modifications of the TH2 response from a B-cell perspective. J Allergy Clin Immunol. 2004;113(5):983-6.

82. Jensen-Jarolim E, Achatz G, Turner MC, Karagiannis S, Legrand F, Capron M, et al. AllergoOncology: the role of IgE-mediated allergy in cancer. Allergy. 2008;63(10):1255-66.

83. Teo PZ, Utz PJ, Mollick JA. Using the allergic immune system to target cancer: activity of IgE antibodies specific for human CD20 and MUC1. Cancer Immunol Immunother. 2012;61(12):2295-309.

84. Karagiannis P, Singer J, Hunt J, Gan SK, Rudman SM, Mechtcheriakova D, et al. Characterisation of an engineered trastuzumab IgE antibody and effector cell mechanisms targeting HER2/neu-positive tumour cells. Cancer Immunol Immunother. 2009;58(6):915-30.

85. Karagiannis SN, Josephs DH, Karagiannis P, Gilbert AE, Saul L, Rudman SM, et al. Recombinant IgE antibodies for passive immunotherapy of solid tumours: from concept towards clinical application. Cancer Immunol Immunother. 2012;61(9):1547-64. 